\title{
Desquamative interstitial pneumonia: Risk factors, laboratory and bronchoalveolar lavage findings, radiological and histopathological examination, clinical features, treatment and prognosis (Review)
}

\author{
ÖZLEM ERÇEN DIKEN ${ }^{1}$, AYSUN ŞENGÜL ${ }^{2}$, AYSSE COŞKUN BEYAN ${ }^{3}$, \\ ÖMER AYTEN ${ }^{4}$, LEVENT CEM MUTLU ${ }^{5}$ and OĞUZHAN OKUTAN ${ }^{4}$
}

\begin{abstract}
${ }^{1}$ Department of Chest Diseases, Hitit University School of Medicine, 19100 Çorum; ${ }^{2}$ Department of Chest Diseases, Kocaeli Derince Education and Research Hospital, 41900 Kocaeli; ${ }^{3}$ Department of Chest Diseases, Dokuz Eylül University School of Medicine, 35800 İzmir; ${ }^{4}$ Department of Chest Diseases, GATA Education and Research Hospital, 34744 İstanbul; ${ }^{5}$ Department of Chest Diseases, Namık Kemal University School of Medicine, 59000 Tekirdağ, Turkey
\end{abstract}

Received December 12, 2016; Accepted June 29, 2017

DOI: $10.3892 /$ etm.2018.7030

\begin{abstract}
Desquamative interstitial pneumonia is a type of smoking-associated major idiopathic interstitial pneumonia, which is characterized by accumulation of alveolar macrophages in alveolar lumens and septa and develops secondary to mainly active or passive exposure to cigarette smoke. Desquamative interstitial pneumonia mostly occurs in male smokers in association with non-specific symptoms responsive to steroid therapy and has a better prognosis than usual interstitial pneumonia. To date, no large-scale clinical studies have been performed on desquamative interstitial pneumonia patients. Factors responsible for the scarcity of data on the clinical course of this condition include the retrospective nature of the available information as well as its rare occurrence. Despite this, a general consensus exists as to the nature of its symptoms, association with smoking, age and gender distribution, findings of respiratory function tests, steroid responsivity and mortality. The objective of the present review article was to report on desquamative interstitial pneumonia and to describe its etiology, risk factors and clinical features, as well as the laboratory, bronchoalveolar lavage, radiological and histopathological findings, and the treatment and prognosis of affected patients.
\end{abstract}

Correspondence to: Dr Özlem Erçen Diken, Department of Chest Diseases, Hitit University School of Medicine, Ciftlik Cayırı Road, 45 Fen-Edebiyat Fakultesi Yerleskesi, 19100 Çorum, Turkey E-mail: oercen@hotmail.com

Key words: desquamative interstitial pneumonia, idiopathic interstitial pneumonias, interstitial pneumonia, lung diseases, pulmonary, smoking

\section{Contents}

1. Introduction

2. Etiology

3. Risk factors

4. Diagnosis

5. Clinical features

6. Treatment and prognosis

\section{Introduction}

Idiopathic interstitial pneumonias (IIPs) are a group of heterogeneous diseases with unknown etiology, characterized by pulmonary parenchymal distortion caused by varying amounts of fibrosis and inflammation, classified under the heading of diffuse parenchymal lung diseases. While IIPs have been reported since the 19th century, it was in 2002 that the American Thoracic Society (ATS) and the European Respiratory Society (ERS) were the first to define and categorize this condition into seven groups considering clinical, radiological and histopathological findings (Table I) (1), and this classification was revised by the ATS and ERS in 2013 (2). The current classification divides IIPs into three groups: Major IIP, rare IIP and unclassifiable IIP (Table II). Major IIP is further divided into three groups, namely chronic fibrosing IIPs, smoking-associated IIPs and acute or sub-acute IIPs (Table III).

Desquamative interstitial pneumonia (DIP) is a major type of smoking-associated IIP, which is characterized by accumulation of alveolar macrophages in alveolar lumens and septa and develops secondary to mainly active or passive exposure to cigarette smoke. It was first defined in 1965 by Liebow et al (3), who described lesions exhibiting extensive alveolar cell proliferation and desquamation associated with mild thickening in distal airways, but not with necrosis (4). The disease was earlier named as such based on the assumption that it was caused by desquamation of alveolar epithelium into the alveoli. Although 
the ATS considered 'alveolar macrophage pneumonia' as a more explanatory definition in 2002, this was renounced later (1).

The prevalence of DIP is not exactly known. Global or national epidemiological data are usually for idiopathic pulmonary fibrosis (IPF), which is the most common form of IIPs. No epidemiological data are available for rare forms of IIP, such as DIP; however, a limited number of case-based studies are available (5).

\section{Etiology}

Despite the more common occurrence in the 4th or 5th decade of life, pediatric cases have also been described in whom surfactant pathology rather than smoking has been implicated. Also smoking-associated pediatric cases have been described (1). The male-to-female ratio is $2: 1$.

While $100 \%$ of respiratory bronchiolitis-associated interstitial lung disease (RB-ILD) cases are linked with cigarette smoking, this figure is $90 \%$ for DIP. In addition to smoking, other factors such as systemic disease, infections, environmental/occupational exposure to hazardous agents as well as drugs may be associated with DIP. Although RB-ILD does not occur in children, DIP may rarely be seen in children. In contrast with the significant male predominance (factor 2:1) among DIP cases, there is no marked predominance in RB-ILD. The two conditions generally occur in the 4 th to 5 th decades of life (6).

With regard to the link between DIP and IPF, a less marked association with cigarette smoking exists for IPF (41-83\% of cases). IPF mostly occurs in the middle-aged or elderly population, with a reported male-to-female ratio between 1:1 and 2:1. It may rarely occur during childhood (6).

\section{Risk factors}

Smoking. The most important widely-recognized factor in the etiology of DIP is the active or passive exposure to cigarette smoke (7). It was reported in $58-91 \%$ of smokers $(4,6,8-10)$. Vassollo (11) described smoking as the most important factor in DIP etiology. Craig et al (12) assessed histopathologically confirmed interstitial pneumonia cases and detected a smoking history in 12 of 20 DIP cases, a number which they concluded to be significantly higher compared with that among RB cases. Ryu et al (13) emphasized smoking in the etiology of DIP and stressed that progressive and fatal cases had a history of heavy smoking.

While an association between smoking and DIP has been fully demonstrated, DIP is also seen in either non-smokers or smoking quitters. This implies the involvement of other etiological risk factors such as environmental or occupational exposure, accompanying diseases or medication use, with or without smoking.

Occupational or environmental exposure to hazardous substances. Regarding occupational exposure to hazardous agents in 8 DIP cases with no smoking history in the study by Craig et al (12), diesel or fire smoke, or beryllium exposure had occurred in these cases. In their study on a series of 10 cases, Moon et al (14) detected solder smoke and occupational wood dust exposure in two different non-smoker cases.
Another important occupation affecting DIP is the textile industry. Lougheed et al (15) reported biopsy-based DIP cases in textile workers employed at cotton/polyester factories. A study performed on 88 textile workers with DIP included five cases with no current smoking status, of which two were non-smokers and the remaining three had a prior smoking history. The authors concluded that a possible factor responsible for DIP development may be aflatoxin inhalation in the workplace. They reported that DIP may develop after exposure to substances including asbestos, talc, graphite, silica and aluminum (15). Liebow and Carrington (16) reported on DIP cases associated with exposure to tungsten cobalt. In a study on the effects of metals on the lung, Nemery (17) suggested that desquamative and giant-cell interstitial pneumonias may occur due to cobalt exposure. Asbestos-associated DIP cases were reported by Corrin and Price (18) in a shipyard worker and by Freed et al (19) in a construction worker who was employed for 32 years. Hull and Abraham (20) reported exposure to aluminum welding smoke as a risk factor for DIP. A different type of occupational exposure as a risk factor was pointed out by Nakazawa et al (21), who presented a radiologically and histopathologically confirmed DIP case who had been subjected to heavy exposure to occupational waterproof spray. Despite the presence of a smoking history, this occupational factor was regarded to be responsible for the disease. All of these findings, in spite of mostly being derived from case-based studies, demonstrated that environmental or occupational exposure to hazardous substances may have an important role in the etiology of DIP.

Psychotropic substance or medication use and chronic diseases. DIP cases associated with chronic drug or psychotropic drug use have been reported. Carrington et al (22) suggested marijuana use as an etiological factor. Pathologically confirmed DIP cases developed secondary to marijuana use and their specimens revealed gold-brown particle-laden macrophages, which was reported to be a distinctive feature of smoking-associated DIP (21). Gill (23) also presented a cannabis-associated case. Certain drugs, including macrolides, sirolimus, nitrofurantoin, sulfasalazine and tocainide were reported to be associated with DIP $(21,24)$. Sirolimus is an immunosuppressive agent whose application is indicated in solid organ transplant patients, amongst whom a large number of pulmonary toxicity cases were reported after sirolimus use. Under circumstances where post-transplant deterioration, dyspnea and hypoxia occur without any evidence of infection, this deterioration may be associated with DIP (25).

DIP was also demonstrated to occur during chronic diseases. A study on 26 DIP cases by Tubbs et al (4) reported that $58 \%$ of subjects had a history of smoking, and that rheumatologic disorders may have been responsible for the disease in the remaining patients. Ishii et al (26), who presented 24 cases where DIP and rheumatologic disease were comorbid, detected positivity of certain markers such as rheumatoid factor and anti-nuclear antibody, and recommended that diagnosis of DIP is established upon histopathological evidence. Kawabata et al (27) reported 20 DIP cases emerging during systemic lupus erythematosus.

There are also case presentations showing an association between DIP and infectious diseases. Iskandar et al (28) 
Table I. Histological and clinical classification of interstitial pneumonia.

Histological pattern

Usual interstitial pneumonia

Non-specific interstitial pneumonia

Organized Pneumonia

Diffuse alveolar injury

Respiratory bronchiolitis

Desquamative interstitial pneumonia

Lymphoid interstitial pneumonia
Clinical-radiological-pathological diagnosis

Idiopathic pulmonary fibrosis/cryptogenic fibrosing alveolitis Non-specific interstitial pneumonia

Cryptogenic organized pneumonia

Acute interstitial pneumonia

Respiratory bronchiolitis interstitial lung disease

Desquamative interstitial pneumonia

Lymphoid interstitial pneumonia
Table II. American thoracic Society/European respiratory society classification of IIP from 2013.

IIP classification Pathology

\begin{tabular}{ll}
\hline Major IIP & Idiopathic pulmonary fibrosis \\
& Idiopathic nonspecific interstitial \\
& pneumonia \\
& Respiratory bronchiolitis interstitial \\
& lung disease \\
& Desquamative interstitial pneumonia \\
& Cryptogenic organized pneumonia \\
& Acute interstitial pneumonia \\
& Idiopathic lymphocytic interstitial \\
pneumonia & Idiopathic pleuroparenchymal \\
fibroelastosis
\end{tabular}

Unclassified IIP

IIP, idiopathic interstitial pneumonia.

reported on the development of DIP due to immunological response mechanisms during hepatitis $\mathrm{C}$ infection. Similarly, Hasegawa et al (29) reported DIP in a 72-year-old patient with chronic hepatitis $\mathrm{C}$ infection who had no history of active or passive smoking. The condition was thought to occur secondary to an immunological response (29). Cytomegalovirus (CMV) infection was also reported to be involved in the etiology of DIP. Schroten et al (30) reported a case of DIP in an 8-month-old infant, developed after CMV infection. Sung et al (31) reported a DIP case which occurred during CMV and aspergillus infections in a renal transplant patient.

Rare causes of DIP have also been reported. Arai et al (32) presented a DIP case developed after receiving a tattoo, which was attributed to a foreign body reaction. While the most recognized etiological factor is exposure to cigarette smoke, DIP may also result from chronic diseases, medication use and occupational or environmental exposure to various substances, as mentioned above. In particular, DIP should be considered in rheumatologic disease and in transplant patients with new onset of radiological alterations and clinical deterioration in the absence of infection.

\section{Diagnosis}

Laboratory and bronchoalveolar lavage (BAL) findings. Laboratory tests usually do not reveal any abnormal findings (3). Certain patients were reported to have polycythemia, which was thought to be associated with respiratory insufficiency (3). A study reported elevated lysozyme levels (33). Another study reported increased levels of erythrocyte sedimentation rate, lactate dehydrogenase, immunoglobulin (Ig)G, IgE and interleukin-6 (34).

Slight elevations in eosinophil, neutrophil, lymphocyte and macrophage counts in the BAL fluid have been reported $(27,34,35)$. However, it should be kept in mind that these laboratory and BAL findings are non-specific and to date, no specific sign has been defined.

\section{Radiological finding}

Radiological diagnosis of DIP. Chest X-ray findings are non-specific (Fig. 1; patient provided informed consent for inclusion in the present study). While patchy ground-glass opacities located peripherally in lower zones are observed in certain cases, others have normal chest X-rays (1).

Diagnostic radiological findings are rather apparent from thoracic high-resolution computed tomography (HRCT; Fig. 2; patient provided informed consent for inclusion in the present study). An invariable HRCT finding is the presence of a diffuse ground-glass appearance, usually symmetrical and frequently involving the middle and lower zones $(6,36,37)$. While involvement of upper zones is seen in most cases, their predominant involvement is relatively rare. All regions may be affected, although subpleural involvement is most common. Other HRCT findings include irregular lines and traction bronchiectases indicating parenchymal distortion (38). Peripheral microcysts implying dilated bronchioles and alveolar ducts may be seen (39). Honeycomb appearance is not common.

Differential diagnosis. Differential diagnoses should include RB-ILD, hypersensitivity pneumonia and non-specific interstitial pneumonia (NSIP). Certain features outlined below may help to rule out these diagnoses. At times, HRCT findings of RB-ILD may include centrilobular micronodules, ground-glass appearance, linear reticular appearance, atelectasis and emphysema (40-43). Centrilobular nodules and patchy ground-glass appearance tend to be diffuse with no predominance of any zone, unlike the appearance in DIP (44). Emphysema and patchy hypoattenuation are mainly seen in lower zones. 
Table III. Classification of major IIP.

Category/clinical-radiological-pathological diagnosis

Morphological pattern

IIP with chronic fibrosis

Idiopathic pulmonary fibrosis

Idiopathic non-specific interstitial pneumonia

IIP associated with smoking

Respiratory bronchiolitis interstitial lung disease

Desquamative interstitial pneumonia

Acute/sub-acute IIP

Cryptogenic organized pneumonia

Acute interstitial pneumonia
Usual interstitial pneumonia

Non-specific interstitial pneumonia

Respiratory bronchiolitis

Desquamative interstitial pneumonia

Organized pneumonia

Diffuse alveolar injury

IIP, idiopathic interstitial pneumonia.

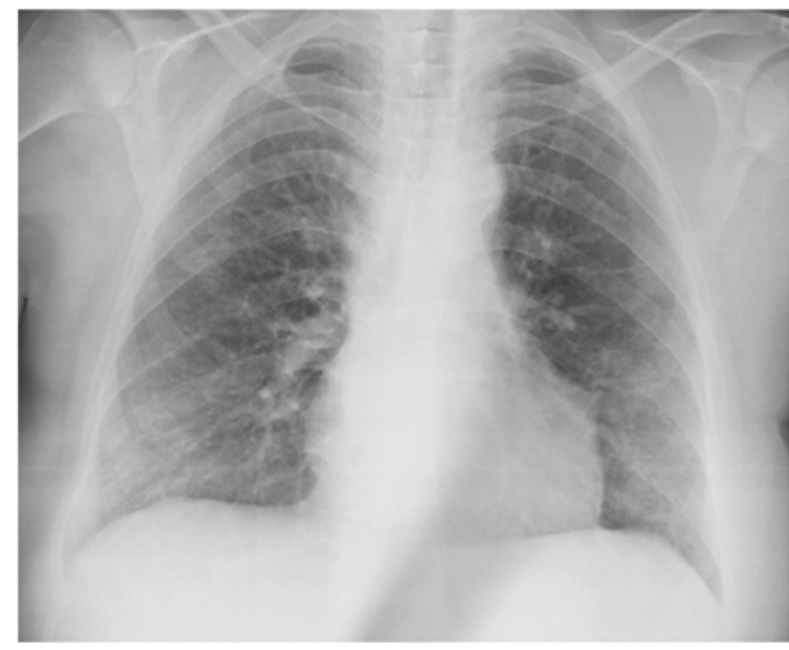

Figure 1. A female patient (age, 55 years) was admitted with chronic cough. Reticular densities were seen on posteroanterior chest X-ray.

Radiological findings of NSIP often consists of bilateral, symmetrical and subpleural ground-glass appearance, which is at times superposed by irregularly linear or reticular opacities or traction bronchiectases $(39,45,46)$. Chronic hypersensitivity pneumonia displays at ground-glass appearance, millimetric centrilobular nodules and mosaic perfusion pattern associated with air entrapment in HRCT $(47,48)$. In addition, certain patients may have a honeycomb appearance (49).

\section{Histopathological examination}

Histopathological diagnosis of DIP. Due to non-specific laboratory, BAL and radiological findings, surgical biopsy is indicated in cases with suspected IIP with no classical usual interstitial pneumonia (UIP) pattern on HRCT, as recommended by the ATS and ERS $(1,50)$.

When first described, the predominant histological feature of the disease was thought to be desquamation of alveolar epithelial cells, and hence it was named DIP (3). However, electron microscopy images indicated macrophage accumulation in alveoli rather than desquamation of

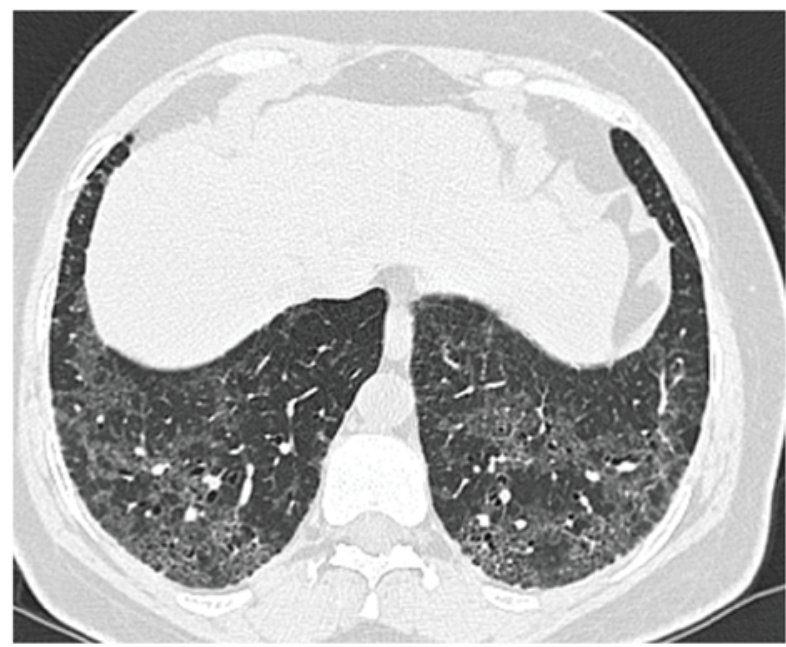

Figure 2. Disorganized ground glass opacity, interlobular septal thickness and minimal honeycomb-like structures were seen on high-resolution computed tomography of the thorax. This is the same patient as presented in Fig. 1.

epithelial cells (4). The major characteristic of DIP is proliferation of pneumocytes over the course of alveolar septa and the presence of numerous macrophages, diffusely distributed along with pulmonary acini within alveoli $(1,10,51)$. These macrophages are termed smoker's macrophages, and exhibit eosinophilic cytoplasm and fine granular light brown pigments (10). Fine granular iron may be seen in the cytoplasm of macrophages (52), multinuclear giant cells are frequent $(3,5)$, and eosinophil and lymphoid aggregates may be observed $(1,3,4)$. The alveolar structure is usually preserved despite mild chronic interstitial inflammation. Albeit rare, interstitial fibrosis may be seen. Emphysema is usually observed, but no or minimal honeycomb appearance is present (12).

Differential diagnosis based on histopathology. DIP is listed among smoking-associated IIPs along with RB-ILD and pulmonary Langerhans cell histiocytosis (PLCH) $(12,35)$. RB is a commonly incidental histopathological lesion of smokers, 
being mainly asymptomatic (53). RB-ILD is a type of RB characterized by respiratory symptoms as well as radiological and spirometric abnormalities observed in certain smokers. Based on histological findings, of RB could not be differentiated from RB-ILD (54). Although these two clinical entities have distinct diagnostic criteria, histopathological differentiation is compelling (2). The major histological finding in RB-ILD is accumulation of alveolar macrophages in respiratory bronchioles. The most important difference between DIP and RB-ILD is the diffuse and uniform character of this accumulation and lesions in DIP, as compared with the bronchiolocentric character of RB-ILD (40). Unlike in DIP, biopsy of RB-ILD reveals less interstitial fibrosis, and less eosinophil and lymphoid follicles in the interstitium are seen (12). Giant cells are not identified in RB-ILD patients. Since RB-ILD as well as DIP are associated with smoking and smokers with other ILDs have common histopathological features with RB-ILD and DIP, the diagnosis of the latter two conditions may only be established in the absence of signs of ILD (55-58).

NSIP should also be kept in mind for the differential diagnosis of DIP. Varying degrees of fibrosis are seen during histopathological examination of fibrotic NSIP (59). While certain patients have patchy fibrosis due to remodeling of the lung (60), a more diffuse involvement with preservation of the alveolar structure may also be observed. Airspace macrophages are not present. In certain smoking patients, differential diagnosis of DIP and fibrotic NSIP based on radiological or histopathological findings is compelling. It has been suggested that DIP may transform into fibrotic NSIP and certain NSIP cases may be associated with smoking (26), which still remains controversial.

The major histological characteristics of early PLCH, a smoking-associated ILD, is the presence of peribronchial nodules containing Langerhans and inflammatory cells (61). Not grouped among IIPs, airspace enlargement with fibrosis [also termed smoking-associated interstitial fibrosis (SRIF)] and combined pulmonary fibrosis and emphysema (CPFE) are the two conditions histopathologically observed in smokers, and which should be distinguished from DIP. SRIF is a recently described histological pattern (62). It was defined after observation of certain alterations in non-neoplastic pulmonary areas of smoking lung cancer patients who underwent lobectomy $(57,62,63)$. Histopathological observations are incidentally made in these asymptomatic patients. They have mainly sub-pleural emphysematous areas and smoker's macrophages within alveoli. Thickened alveolar septa are seen due to hyperplastic smooth-muscle fibers and eosinophilic collagen structures. While SRIF is an incidentally detected radiological and histopathological condition, CPFE, which is rather a comorbid pathology of IPF, has clinical signs associated with emphysema and interstitial fibrosis (2).

\section{Clinical features}

DIP, a chronic disease, mostly occurs in male smokers in association with non-specific symptoms responsive to steroid therapy and has a better prognosis than UIP. To date, no large-scale clinical studies have been performed in DIP patients. Factors responsible for the scarcity of data on the clinical course of this condition include the retrospective nature of the available information as well as its rare occurrence. Despite this, a general consensus exists as to the nature of its symptoms, association with smoking, age and gender distribution, findings of respiratory function tests, steroid responsivity and mortality (Table IV).

In their retrospective study, Ryu et al (13) examined 33 patients with DIP and 12 patients with RB-ILD. The patient characteristics in these subjects are summarized in Table IV. In that study, a total of 21 DIP patients (91\%) received corticosteroids and 4 quit smoking (27\%). Improvement was found in 1 patient $(5 \%)$, while 12 patients $(63 \%)$ had stable disease, while the disease deteriorated in 1 patient $(5 \%)$ and 5 patients succumbed to their disease $(26 \%)$. The causes of death included respiratory failure in 3 , lung cancer in 1 and hepatic carcinoma in another.

In the study by Kawabata et al (34), a total of 31 DIP patients were followed-up for a duration of 99 months. Their patient characteristics are depicted in Table IV. Patients received pulsed or oral steroids at a daily dose of 15-80 mg, with clinical improvement in $90 \%$ of the cases. Seventy patients quit smoking prior to or after treatment. Deaths occurred due to DIP progression, lung cancer, fulminant pulmonary disease after lobectomy and diffuse alveolar disease in one patient each and due to causes not associated with lung disease in another four patients. Lobectomy was performed in three patients due to lung cancer. The 10-year survival rate was $78 \%$.

Craig et al (12) reported an average survival of 8.8 years for non-smokers and 7 years for smokers during the follow-up of their patients. Due to the presence of occupational exposure to hazardous substances in their patient group, the authors concluded that it was not possible to definitely determine the causative role of DIP in the development of clinical signs.

Bressieux-Degueldre et al (64) reported on a 30-month old female patient who presented with respiratory failure. Physical examination revealed the presence of respiratory rales on auscultation. After a diagnosis of DIP was established, corticosteroid treatment was commenced and the patient was reported to be oxygen-dependent at 2 years of follow-up. DIP represents the most common form of pediatric interstitial lung disease, which has been linked with a genetic defect in surfactant proteins in children. A possible diagnosis of interstitial lung disease should be suspected in children with cough, dyspnea or tachypnea lasting $>3$ months. Aggressive nutritional support as well as preventive measures against infections are important in the management of children with DIP. Although corticosteroids and immunosuppressive agents are recommended, the prognosis is poor. Lung transplantation represents a therapeutic option during terminal disease.

A 44-year-old patient presenting with shortness of breath, right-sided pleuritic chest pain and orthopnea was described by Behnia and Cummings (65). The patient was found to be sub-febrile and tachycardic, and also had rales in the lower zones of the lung on auscultation. Pulmonary angiography revealed no filling defects. Clinically, the patient was hypotensive and died at 5 days after admission; the diagnosis was established on autopsy.

In addition to those presenting with cough, dyspnea or chest pain, patients presenting with non-specific symptoms such as slightly increased body temperature, myalgia, weight loss, fatigue or respiratory failure have also been reported $(66,67)$. 
Table IV. Clinical and functional findings and the disease course in patients with desquamative interstitial pneumonia.

\begin{tabular}{|c|c|c|c|c|}
\hline Parameter & Ryu et al (13) & Kawabata et al (34) & Craig et al (12) & Yousem et al (10) \\
\hline $\mathrm{N}$ & 23 & 31 & 20 & 36 \\
\hline Male sex & $11 / 23(48)$ & 29/31 (93.5) & $12 / 20(60)$ & $26 / 36(72.2)$ \\
\hline Age (years) & $46 \pm 10$ & $55 \pm 13$ & 43 & $42(17-67)$ \\
\hline Smoking status (current) & $18 / 23(78)$ & 28/30 (93) & $12 / 20(60)$ & 33/36 (91.6) \\
\hline Smoking status (previous) & $2(8)$ & & & \\
\hline Smoking history (pack years) & $38 \pm 21$ & $52 \pm 41$ & & $36(10-71)$ \\
\hline \multicolumn{5}{|l|}{ Symptoms } \\
\hline None & $1(4)$ & & & $5 / 34(15)$ \\
\hline Dyspnea & $20(87)$ & & & $29 / 34(85)$ \\
\hline Cough & $10(43)$ & & & $26 / 32(81)$ \\
\hline Sputum & & & & $17 / 33(52)$ \\
\hline Chest pain & $4(17)$ & & & \\
\hline \multicolumn{5}{|l|}{ Physical signs } \\
\hline Inspiratory crackles & $13(57)$ & & & $5 / 9(56)$ \\
\hline Digital clubbing & $6(26)$ & & & $15 / 36(42)$ \\
\hline \multicolumn{5}{|l|}{ Pulmonary function } \\
\hline Restrictive & $6(30)$ & & & \\
\hline Obstructive & $3(15)$ & & & \\
\hline Low diffusion capacity only & $7(35)$ & & & \\
\hline Normal & $4(20)$ & & & \\
\hline Total lung capacity, PP & $84.8 \pm 18.8$ & & & $94(43-133)$ \\
\hline $\mathrm{FVC}, \mathrm{PP}$ & $74.1 \pm 16.7$ & $84 \pm 23(\mathrm{VC})$ & & $68(33-124)$ \\
\hline DLCO, PP & $52.8 \pm 16.7$ & & & $45(32-78)$ \\
\hline Oxygen saturation at rest, $\%$ & $93.8 \pm 3.6$ & & & \\
\hline Oxygen saturation with exercise, $\%$ & $89.4 \pm 5.1$ & & & \\
\hline $\mathrm{PaO}_{2}, \mathrm{mmHg}$ & & $79 \pm 11$ & & \\
\hline Mortality, \% & $26 \%$ & $78 \%$ (10 years) & & $8 / 36(32)$ \\
\hline
\end{tabular}

Values are expressed as the Mean \pm standard deviation, $\mathrm{n}(\%), \mathrm{n} /$ total $(\%)$, then mean value or mean (range). FVC, forced vital capacity; $\mathrm{PP}$, percent predicted; DLCO, diffusing capacity of the lungs for carbon monoxide; $\mathrm{PaO}_{2}$, partial pressure of oxygen; $\mathrm{VC}$, vital capacity.

Yousem et al (10) assessed 36 DIP patients with chronic symptoms. The clinical characteristics of these patients are summarized in Table IV. In this retrospective evaluation, 14 patients $(56 \%)$ exhibited improvement during follow-up, while $3(12 \%)$ were stable and 8 patients $(32 \%)$ died. Comparison between RB-ILD and DIP patients revealed an average diffusion capacity of 62 and $45 \%$ in these groups, respectively.

The most common symptoms of DIP include dyspnea and dry cough of insidious onset that may last for weeks or months. In addition, patients with respiratory failure, fever, fatigue and weakness have been reported. Digital clubbing is present in nearly half of the cases (1). Chest pain and weight loss may also occur. Hemoptysis is rare, as are asymptomatic cases. Cyanosis may be seen. DIP may occur in association with connective tissue disorders such as scleroderma, lupus or rheumatoid arthritis, and their symptoms may accompany those of DIP (68).

In patients with DIP, the lung volume is normal or mild restrictive abnormalities may be detected, with moderately reduced diffusing capacity of the lungs for carbon monoxide, which is an indicator of the severity of the underlying disorder. In the assessment of the severity of the functional impairment in DIP, emphysema, which is a frequent co-morbidity, may be a confounding factor (69). Cor pulmonale is rare and hypoxia occurs in the advanced stages of the disease (70).

In each of the two forms of smoking-associated IIPs, DIP and RB-ILD, cough and shortness of breath represent the most common symptoms with an insidious onset (6). Symptoms and clinical features are non-specific in DIP and RB-ILD. The nature of dyspnea in DIP and RB-ILD is slowly progressing exercise dyspnea (69). While rales on auscultation may be heard in each of the two conditions, digital clubbing is more common in DIP. Approximately $60 \%$ of DIP patients are found to have rales on auscultation on physical examination. Respiratory function tests reveal a restrictive pattern in DIP, while a mixed defect or normal result may be observed in RB-ILD (6). RB-ILD and DIP respond favorably to steroids with good prognosis, and a complete response may occur.

In IPF, the onset is insidious. Dry cough and shortness of breath comprise the most common symptoms. Almost all 
patients have rales on auscultation and digital clubbing is more common (50-70\%). Compared to IPF, a less marked effect is observed in respiratory function tests in DIP (6).

\section{Treatment and prognosis}

Prognosis in DIP is usually favorable and the majority of the patients improve with quitting smoking and corticosteroid therapy. The 10 -year survival rate is $\sim 70 \%$ (1), with a mortality rate between 6 and 28\% (71). Of the untreated patients, almost two thirds have a poor prognosis (6). Despite an insidious onset, the disease may exhibit a rapidly progressive course. Progression to severe fibrosis is rare (70).

Compared to IPF, DIP has a more moderate prognosis with a better response to anti-inflammatory treatment. The mainstay of treatment is quitting smoking, which may, on its own, be sufficient in certain cases (72). Environmental factors and drugs are also implicated in the development of DIP $(15,18,73,74)$. Therefore, termination of any probable environmental risk factors is reasonable. In a study assessing a series of 5 cases of occupational DIP, Lougheed et al (15) reported improvement in two cases after moving off the workplace requiring no steroid treatment, and chronic respiratory insufficiency despite steroid treatment in the three remaining cases.

Systemic steroid treatment is recommended in moderately or severely symptomatic patients who progressed despite quitting smoking. While certain patients respond to this treatment based on clinical and radiological findings, others remain stable or the disease progresses (10,75-77). Ryu et al (13) followed 23 DIP patients for 12 years and reported symptomatic improvement in $24 \%$ of cases that were initiated with steroid treatment. However, they also reported recurrence in certain patients after termination of steroid therapy, even in smoking quitters, where recurrence rates were higher in those resuming smoking or with passive cigarette smoking. It remains to be elucidated whether improvement after steroid initiation depends on steroid treatment or termination of smoking, or results from the natural course of the disease. However, observational studies indicated progression in most of the patients who did not receive any treatment (22). Although no randomized controlled clinical trial proving its efficacy is available, initiation of steroid treatment in all patients with diagnosis of DIP appears to be a reasonable approach with continuance of the treatment upon clinical, radiological and functional improvement and discontinuance in case of no response. Initial steroid treatment consists of 40-60 mg/day for 6 weeks, followed by tapering and cessation of the treatment within 6-9 months (33).

Based on the potential anti-inflammatory effects of macrolides in steroid-refractory cases, Knyazhitskiy et al (78) reported rapid and dramatic improvement in all clinical and radiological parameters with clarithromycin treatment in a patient who was refractory to steroid therapy. Similarly, in a case where no response was obtained after initiation of oral steroids, clinical and radiological improvement was observed at one month after reduction of the steroid dose and addition of clarithromycin (79).

Data on cytotoxic and immunosuppressive agents for treating DIP are inconclusive. A limited number of studies reported favorable outcomes after azathioprine and methotrexate treatment (66). Lung transplantation may be the treatment of choice in cases with severe and persistent disease. However, recurrence may also be seen after transplantation (80-82).

\section{Acknowledgements}

The authors are grateful for the support of Professor Arzu Mirici (Department of Pulmonary Diseases, Çanakkale University School of Medicine, Çanakkale, Turkey) and President of the Young Academicians Group (GEAK) of the Turkish Respiratory Society, who contributed to the planning of this review. All of the authors of the present study are also members of GEAK.

\section{References}

1. American Thoracic Society; European Respiratory Society: American Thoracic Society/European Respiratory Society International Multidisciplinary Consensus Classification of the Idiopathic Interstitial Pneumonias. This joint statement of the American Thoracic Society (ATS), and the European Respiratory Society (ERS) was adopted by the ATS board of directors, June 2001 and by the ERS Executive Committee, June 2001. Am J Respir Crit Care Med 165: 277-304, 2002.

2. Travis WD, Costabel U, Hansell DM, King TE Jr, Lynch DA, Nicholson AG, Ryerson CJ, Ryu JH, Selman M, Wells AU, et al: An official American Thoracic Society/European Respiratory Society Statement: Update of the international multidisciplinary classification of the idiopathic interstitial pneumonias. Am J Respir Crit Care Med 188: 733-748, 2013.

3. Liebow AA, Steer A and Billingsley JG: Desquamative interstitial pneumonia. Am J Med 39: 369-440, 1965.

4. Tubbs RR, Benjamin SP, Reich NE, McCormack LJ and Van Ordstrand HS: Desquamative interstitial pneumonitis. Cellular phase of fibrosing alveolitis. Chest 72: 159-165, 1977.

5. Okutan $\mathrm{O}$ and Çalışkan T: Smoking-related Interstitial Lung Diseases. Eurasian J Pulmonol 13: 131-139, 2011.

6. Ryu JH, Colby TV, Hartman TE and Vassallo R: Smoking-related interstitial lung diseases: A concise review. Eur Respir J 17: 122-132, 2001.

7. Ischander M, Fan LL, Farahmand V, Langston C and Yazdani S: Desquamative interstitial pneumonia in a child related to cigarette smoke. Pediatr Pulmonol 49: E56-E58, 2014.

8. Well AU, Nicholson AG and Hansell DM: Challenges in pulmonary fibrosis. 4: Smoking induced diffuse interstitial lung disease. Thorax 62: 904-910, 2007.

9. Bradley B, Branley HM, Egan JJ, Greaves MS, Hansell DM, Harrison NK, Hirani N, Hubbard R, Lake F, Millar AB, et al: Interstitial lung disease guidelines: The British Thoracic Society in collaboration with the Thoracic Society of Australia and New Zealand and the Irish Thoracic Society. Thorax 63 (Suppl 5): v1-v58, 2008

10. Yousem SA, Colby TV and Gaensler EA: Respiratory bronchiolitis-associated interstitial lung disease and its relationship to desquamative interstitial pneumonia. Mayo Clin Proc 64: 1373-1380, 1989.

11. Vassallo R: Diffuse lung diseases in cigarette smokers. Semin Respir Crit Care Med 33: 533-542, 2012.

12. Craig PJ, Wells AU, Doffman S, Rassl D, Colby TV, Hansell DM, Du Bois RM and Nicholson AG: Desquamative interstitial pneumonia, respiratory bronchiolitis and their relationship to smoking. Histopathology 45: 275-282, 2004.

13. Ryu JH, Myers JL, Capizzi SA, Douglas WW, Vassallo R and Decker PA: Desquamative interstitial pneumonia and respiratory bronchiolitis-associated interstitial lung disease. Chest 127: $178-184,2005$.

14. Moon J, du Bois RM, Colby TV, Hansell DM and Nicholson AG: Clinical significance of respiratory bronchiolitis on open lung biopsy and its relationship to smoking related interstitial lung disease. Thorax 54: 1009-1014, 1999.

15. Lougheed MD, Roos JO, Waddell WR and Munt PW: Desquamative interstitial pneumonitis and diffuse alveolar damage in textile workers. Potential Role of Mycotoxins Chest 108: 1196-1200, 1995. 
16. Liebow AA and Carrington CB: The interstitial pneumonias. In: Simon M, Potchen EJ, LeMay M, (eds). Frontiers of pulmonary radiology. 1st edition. New York, Grune and Stratton, pp102-141, 1969.

17. Nemery B: Metal toxicity and the respiratory tract. Eur Respir J 3: 202-219, 1990.

18. Corrin B and Price AB: Electron microscopic studies in desquamative interstitial pneumonia associated with asbestos. Thorax 27: 324-331, 1972.

19. Freed JA, Miller A, Gordon RE, Fischbein A, Kleinerman J and Langer AM: Desquamative interstitial pneumonia associated with chrysotile asbestos fibres. Br J Ind Med 48: 332-337, 1991.

20. Hull MJ and Abraham JL: Aluminum welding fume-induced pneumoconiosis. Hum Pathol 33: 819-825, 2002

21. Nakazawa A, Hagiwara E, Harada S, Yoshida M, Baba T, Okudela K, Takemura T and Ogura T: Surgically proven desquamative interstitial pneumonia induced by waterproofing spray. Intern Med 53: 2107-2110, 2014.

22. Carrington CB, Gaensler EA, Coutu RE, FitzGerald MX and Gupta RG: Natural history and treated course of usual and desquamative interstitial pneumonia. N Engl J Med 298: 801-809, 1978

23. Gill A: Bong lung: Regular smokers of cannabis show relatively distinctive histologic changes that predispose to pneumothorax Am J Surg Pathol 29: 980-982, 2005.

24. Hage P and El Hajje MJ: Nitrofurantoin-induced desquamative interstitial pneumonitis in a 7-year-old child. Pediatr Infect Dis J 30: 363, 2011

25. Feagans J, Victor D, Moehlen M, Florman SS, Regenstein F, Balart LA, Joshi S, Killackey MT, Slakey DP and Paramesh AS: Interstitial pneumonitis in the transplant patient: Consider sirolimus-associated pulmonary toxicity. J La State Med Soc 161: 168-172, 2009.

26. Ishii H, Iwata A, Sakamoto N, Mizunoe $S$, Mukae $H$ and Kadota J: Desquamative interstitial pneumonia (DIP) in a patient with rheumatoid arthritis: Is DIP associated with autoimmune disorders? Intern Med 48: 827-830, 2009.

27. Kawabata Y, Takemura T, Hebisawa A, Ogura T, Yamaguchi T, Kuriyama T, Nagai S, Sakatani M, Chida K, Sakai F, et al: Eosinophilia in bronchoalveolar lavage fluid and architectural destruction are features of desquamative interstitial pneumonia Histopathology 52: 194-202, 2008.

28. Iskandar SB, McKinney LA, Shah L, Roy TM and Byrd RP Jr: Desquamative interstitial pneumonia and hepatitis $C$ virus infection: A rare association. South Med J 97: 890-893, 2004.

29. Hasegawa H, Nakamura Y, Kaida Y, Enomoto N, Hashimoto D Inui N, Suda T and Chida K: A case of desquamative interstitial pneumonia associated with hepatitis $C$ virus infection. Nihon Kokyuki Gakka Zasshi 47: 698-703, 2009 (In Japanese).

30. Schroten H, Manz S, Köhler H, Wolf U, Brockmann M and Riedel F: Fatal desquamative interstitial pneumonia associated with proven CMV infection in an 8 month old-boy. Pediatr Pulmonol 25: 345-347, 1998 .

31. Sung SA, Ko GJ, Kim JY, Kim MG, Lee JE, Kim GI, Jo SK, Cho WY and Kim HK: Desquamative interstitial pneumonia associated with concurrent cytomegalovirus and Aspergillus pneumonia in a renal transplant recipient. Nephrol Dial Transplant 20: 635-638, 2005.

32. Arai T, Inoue Y, Hayashi S, Akira M, Satoru Y, Travis WD and Sakatani M: Intractable desquamative interstitial pneumonia in a tattooed man. Intern Med 45: 1055-1058, 2006

33. Davies G, Wells AU and du Bois RM: Respiratory bronchiolitis associated with interstitial lung disease and desquamative interstitial pneumonia. Clin Chest Med 25: 717-726, vi, 2004.

34. Kawabata Y, Takemura T, Hebisawa A, Sugita Y, Ogura T, Nagai S, Sakai F, Kanauchi T and Colby TV; Desquamative Interstitial Pneumonia Study Group: Desquamative interstitial pneumonia may progress to lung fibrosis as characterized radiologically. Respirology 17: 1214-1221, 2012.

35. Hidalgo A, Franquet T, Giménez A, Bordes R, Pineda R and Madrid M: Smoking-related interstitial lung diseases: Radiologic-pathologic correlation. Eur Radiol 16: 2463-2470, 2006.

36. Hartman TE, Primack SL, Swensen SJ, Hansell D, McGuinness G and Müller NL: Desquamative interstitial pneumonia: Thin-section CT findings in 22 patients. Radiology 187 787-790, 1993.

37. Akira M, Yamamoto S, Hara H, Sakatani M and Ueda E: Serial computed tomographic evaluation in desquamative interstitial pneumonia. Thorax 52: 333-337, 1997.
38. Desai SR, Ryan SM and Colby TV: Smoking-related interstitial lung diseases: Histopathological and imaging perspectives. Clin Radiol 58: 259-268, 2003

39. Mueller-Mang C, Grosse C, Schmid K, Stiebellehner L and Bankier AA: What every radiologist should know about idiopathic interstitial pneumonias. Radiographics 27: 595-615, 2007.

40. Heynemann LE, Ward S, Lynch DA, Remy-Jardin M, Johkoh T and Müller NL: Respiratory bronchiolitis, respiratory bronchiolitis-associated interstitial lung disease, and desquamative interstitial pneumonia: Different entities or part of the spectrum of the same disease process? AJR Am J Roentgenol 173: $1617-1622,1999$.

41. Holt RM, Schmidt RA, Godwin JD and Raghu G: High-resolution CT in respiratory bronchiolitis-associated interstitial lung disease. J Comput Assist Tomogr 17: 46-50, 1993.

42. Essadki O, Chartrand-Lefebvre C, Briere J and Grenier P: Respiratory bronchiolitis: Radiographic and CT findings in a pathologically proven case. Eur Radiol 8: 1674-1676, 1998.

43. Kurumagawa T, Kobayashi H, Kanoh S, Nagata N, Aoki T, Aida S and Tamai S: Respiratory bronchiolitis-associated interstitial lung disease. Nihon Kokyuki Gakkai Zasshi 36: 881-885, 1998 (In Japanese)

44. Park JS, Brown KK, Tuder RM, Hale VA, King Jr TE and Lynch DA: Respiratory bronchiolitis-associated interstitial lung disease: Radiologic features with clinical and pathologic correlation. J Comput Assist Tomogr 26: 13-20, 2002.

45. Kim DS, Collard HR and King TE Jr: Classification and natural history of the idiopathic interstitial pneumonias. Proc Am Thorac Soc 3: 285-292, 2006.

46. Akira M, Inoue G, Yamamoto S and Sakatani M: Non-specific interstitial pneumonia: Findings on sequential CT scans of nine patients. Thorax 55: 854-859, 2000.

47. Silva CI, Churg A and Müller NL: Hypersensitivity pneumonitis: Spectrum of high-resolution CT and pathologic findings. AJR Am J Roentgenol 188: 334-344, 2007.

48. Glazer CS, Rose CS and Lynch DA: Clinical and radiologic manifestations of hypersensitivity pneumonitis. J Thorac Imaging 17: 261-272, 2002

49. Silva CI, Müller NL, Lynch DA, Curran-Everett D, Brown KK, Lee KS, Chung MP and Churg A: Chronic hypersensitivity pneumonitis: Differentiation from idiopathic pulmonary fibrosis and nonspecific interstitial pneumonia by using thin-section CT. Radiology 246: 288-297, 2008

50. Bedrossian CW, Kuhn C III, Luna MA, Conklin RH, Byrd RB and Kaplan PD: Desquamative interstitial pneumonia-like reaction accompanying pulmonary lesion. Chest 72: 166-169, 1977.

51. Nicholson AG: Desquamative interstitial pneumonia. In: Tomashefski JF (ed). Dail and Hammar's Pulmonary Pathology. Berlin, Springer, pp710-712, 2008

52. Travis WD, Colby TV, Lombard CM and Carpenter HA: A clinicopathologic study of 34 cases of diffuse pulmonary hemorrhage with lung biopsy confirmation. Am J Surg Pathol 14: 1112-1125, 1990.

53. Niewoehner DE, Kleinerman J and Rice DB: Pathologic changes in the peripheral airways of young cigarette smokers. N Engl J Med 291: 755-758, 1974

54. Myers JL, Veal CF Jr, Shin MS and Katzenstein AL: Respiratory bronchiolitis causing interstitial lung disease: A clinicopathologic study of six cases. Am Rev Respir Dis 135: 880-884, 1987.

55. Churg A, Müller NL and Wright JL: Respiratory bronchiolitis/interstitial lung disease. Fibrosis, pulmonary functions, and evolving concepts. Arch Pathol Lab Med 134: 27-32, 2010.

56. Fraig M,Shreesha U, Savici D and Katzenstein AL: Respiratory bronchiolitis: A clinicopathologic study in current smokers, ex-smokers, and never-smokers. Am J Surg Pathol 26: 647-653, 2002.

57. Kawabata Y, Hoshi E, Murai K, Ikeya T, Takahashi N, Saitou Y, Kurashima K, Ubukata M, Takayanagi N, Sugita H, et al: Smoking-related changes in the background lung of specimens resected for lung cancer: A semiquantitative study with correlation to postoperative course. Histopathology 53: 707-714, 2008.

58. Tazelaar HD, Wright JL and Churg A: Desquamative interstitial pneumonia. Histopathology 58: 509-516, 2011.

59. Travis WD, Matsui K, Moss J and Ferrans VJ: Idiopathic nonspecific interstitial pneumonia: Prognostic significance of cellular and fibrosing patterns: Survival comparison with usual interstitial pneumonia and desquamative interstitial pneumonia. Am J Surg Pathol 24: 19-33, 2000.

60. Nagai $S$, Kitaichi $M$, Itoh $H$, Nishimura K, Izumi $T$ and Colby TV: Idiopathic nonspecific interstitial pneumonia/fibrosis: Comparison with idiopathic pulmonary fibrosis and BOOP. Eur Respir J 12: 1010-1019, 1998. 
61. Vassallo R, Ryu JH, Colby TV, Hartman T and Limper AH: Pulmonary Langerhans'-cell histiocytosis. N Engl J Med 342: 1969-1978, 2000.

62. Katzenstein AL: Smoking-related interstitial fibrosis (SRIF), pathogenesis and treatment of usual interstitial pneumonia (UIP), and transbronchial biopsy in UIP. Mod Pathol 25 (Suppl 1): S68-S78, 2012.

63. Katzenstein AL, Mukhopadhyay S, Zanardi C and Dexter E: Clinically occult interstitial fibrosis in smokers: Classification and significance of a surprisingly common finding in lobectomy specimens. Hum Pathol 41: 316-325, 2010.

64. Bressieux-Degueldre S, Rotman S, Hafen G, Aubert JD and Rochat I: Idiopathic desquamative interstitial pneumonia in a child: A case report. BMC Res Notes 7: 383, 2014.

65. Behnia MM and Cummings OW: Desquamative interstitial pneumonia masquerading as acute life-threatening pulmonary embolism. Am J Crit Care 13: 199-201, 2004.

66. Gould TH, Buist MD, Meredith D and Thomas PD: Fulminant desquamative interstitial pneumonitis. Anaesth Intensive Care 26: 677-679, 1998.

67. Flusser G, Gurman G, Zirkin H, Prinslo I and Heimer D Desquamative interstitial pneumonitis causing acute respiratory failure, responsive only to immunosuppressants. Respiration 58 : 324-326, 1991

68. Palmucci S, Roccasalva F, Puglisi S, Torrisi SE, Vindigni V, Mauro LA, Ettorre GC, Piccoli M and Vancheri C: Clinical and radiological features of idiopathic interstitial pneumonias (IIPs): A pictorial review. Insights Imaging 5: 347-364, 2014.

69. Caminati A, Cavazza A, Sverzellati N and Harari S: An integrated approach in the diagnosis of smoking-related interstitial lung diseases. Eur Respir Rev 21: 207-217, 2012.

70. Godbert B, Wissler MP and Vignaud JM: Desquamative interstitial pneumonia: An analytic review with an emphasis on aetiology. Eur Respir Rev 22: 117-123, 2013.

71. Hagmeyer L and Randerath W: Smoking-related interstitial lung disease. Dtsch Arztebl Int 112: 43-50, 2015.

72. Matsuo K, Tada S, Kataoka M, Okahara M, Hiramatsu J, Horiba M, Fujimori Y, Takehara H, Okamoto M, Yamadori I and Harada M: Spontaeous remission of desquamative interstitial pneumonia. Intern Med 36: 728-731, 1997.
73. Abraham JL and Hertzberg MA: Inorganic particles associated with desquamative interstitial pneumonia. Chest 80 (1 Suppl): S67-S70, 1981

74. Bone RC, Wolfe J, Sobonya RE, Kerby GR, Stechschulte D, Ruth WE and Welch M: Desquamative interstitial pneumonia following long-term nitrofurantoin therapy. Am J Med 60: 697-701, 1976.

75. Portnoy J, Veraldi KL, Schwarz MI, Cool CD, Curran-Everett D, Cherniack RM, King TE Jr and Brown KK: Respiratory bronchiolitis-interstitial lung disease: Long-term outcome. Chest 131: 664-671, 2007.

76. Hartman TE, Primack SL, Kang EY, Swensen SJ, Hansell DM, McGuinness G and Müller NL: Disease progression in usual interstitial pneumonia compared with desquamative interstitial pneumonia. Assessment with serial CT. Chest 110: 378-382, 1996.

77. Baloira A, Xaubet A, Rodríguez Becerra E, Romero AD, Casanova A and Ancochea J: Desquamative interstitial pneumonia and respiratory bronchiolitis-associated interstitial lung disease: Data from the Spanish patient registry. Arch Bronconeumol 44: 499-503, 2008 (In Spanish).

78. Knyazhitskiy A, Masson RG, Corkey R and Joiner J: Beneficial response to macrolide antibiotic in a patient with desquamative interstitial pneumonia refractory to corticosteroid therapy. Chest 134: 185-187, 2008

79. Park DW, Kim TH, Shon JW, Yoon HJ, Park SS, Jeon SC, Choi YW, Paik SS and Kim H: Near fatal desquamative interstitial pneumonia with bilateral recurrent tension pneumothorax. Sarcoidosis Vasc Diffuse Lung Dis 32: 167-171, 2015.

80. Barberis M, Harari S, Tironi A and Lampertico P: Recurrence of primary disease in a single lung transplant recipient. Transplant Proc 24: 2660-2662, 1992.

81. Verleden GM, Sels F, Van Raemdonck D, Verbeken EK, Lerut T and Demedts M: Possible recurrence of desquamative interstitial pneumonitis in a single lung transplant recipient. Eur Respir J 11: 971-974, 1998

82. King MB, Jessurun J and Hertz MI: Recurrence of desquamative interstitial pneumonia after lung transplantation. Am J Respir Crit Care Med 156: 2003-2005, 1997. 